\section{It's not all academic: nursing admissions and attrition in the United States}

\author{
Erin Horkey \\ University of Toledo, OH, USA
}

\section{Abstract}

Interest in the nursing profession is growing in the United States (US). Currently, there are more applicants for nursing school than nursing school capacities can accommodate. At the same time qualified applicants are unable to enter nursing school related to program capacities, $18 \%$ of admitted students leave nursing schools prior to graduation. The abundance of applicants should make nursing school attrition, in the US, practically nonexistent. US nursing programs must determine more effective criteria for screening applicants so that the students, most likely to succeed, are admitted to programs.

\section{Introduction}

A nursing school admission process is an intricately complex web of criteria used to evaluate potential nursing school candidates. Each school of nursing evaluates potential students using a pre-designed admission formula aiming to identify and admit the students most likely to succeed. Evaluation of admission criteria is an ongoing process as schools struggle to find the combination of factors most predictive of academic success.

The discipline of nursing has been considered both a science and an art that demands a myriad of knowledge, skills, and abilities. ${ }^{1}$ Nurses must maintain professionalism while providing empathic, compassionate care to patients in complex circumstances. ${ }^{2}$ Nurses must be knowledgeable, safe, and competent caregivers; and at the same time have a strong academic foundation. ${ }^{2}$ The special blend of art and academia present in nurses does not exist in everyone. Competent nurses have an innate ability to interact with patients at their worst and partner with them to create the patients greatest hour. ${ }^{1}$ Patients depend on competent nurses to ensure their health and well-being and it is the job of nursing education to foster the development of competent nurses. The use of effective evidence based admission criteria by nursing schools may be the first step in the development of competent nurses.

\section{Nursing admissions and attrition in the United States}

As interest in the nursing profession grows in the United States (US), the number of nursing school applicants is significantly increasing. However, a limited number of qualified faculty and a shortage of clinical placement sites have left nursing schools around the US unable to meet this demand. ${ }^{3,4}$ According to the National League for Nursing (NLN), ${ }^{3}$ in 2011, $80 \%$ of associate degree programs and twothirds of pre-licensure baccalaureate programs turned away qualified applicants due to limited program capacity. ${ }^{3}$ Nationally, in $2011,36.6 \%$ of qualified applicants to pre-licensure baccalaureate programs were denied admission solely based on the number of seats available within nursing programs. ${ }^{4}$

There are an abundance of qualified nursing applicants and high demand for admission into US nursing schools, however, student attrition is an ongoing problem. The average first year attrition rate is $18 \%$ for pre-licensure nursing programs. ${ }^{5}$ Williams $^{6}$ noted that the majority of nursing program attrition occurs within the first year. A significant contributor to attrition is ill prepared students who are unable to meet the academic and clinical demands of nursing curricula. ${ }^{7-9}$ This fact raises a rather troubling question: If students are meeting admission requirements, why are they not prepared to meet the curricular demands? While research has yet to pinpoint why program attrition is so high, one might hypothesize that large scale attrition indicates inadequate admission standards as multiple researches have positively linked students prenursing performance to success in nursing school. ${ }^{7-11}$ Attempts to solve the attrition problem in nursing education has led to significant research into nursing school admission standards in the US.

\section{Current research: academic variables}

Currently, there is a lack of consistency in admission requirements between institutions. Nursing schools individually select which criteria to evaluate when considering a student for admission. Most nursing schools use a combination of quantitative academic factors such as grade point averages (GPA), pre-requisite course grades, and standardized admission examination scores. No evidence based guidelines currently exist for schools when
Correspondence: Erin Horkey, 3000 Arlington Ave., Toledo, OH 43614, USA.

Tel.: 419.383.5873.

E-mail: Erin.Horkey@utoledo.edu

Key words: Nursing school; admission criteria; attrition.

Conflict of interest: the author declares no potential conflict of interest.

Received for publication: 30 November 2015 . Revision received: 17 November 2015. Accepted for publication: 18 November 2015.

This work is licensed under a Creative Commons Attribution NonCommercial 3.0 License (CC BYNC 3.0).

(C) Copyright E. Horkey, 2015

Licensee PAGEPress, Italy

Nursing Reports 2015; 5:4849

doi:10.4081/nursrep.2015.4849

creating and evaluating admission policies. Therefore, the understanding of what best predicts student success is limited. There is minimal research support to link specific admission criteria with an increased retention of students in nursing schools in the US.

The majority of research into admission criteria and attrition in nursing education focuses on quantitative factors. ${ }^{7-12}$ Studies evaluating GPA, standardized admission testing, and pre-requisite course grades predominate the literature. ${ }^{7-12}$ A quantitative research focus is likely because the majority of schools use only quantitative criteria for admission. While trends in academic criteria have been identified, and recommendations made, attrition remains high.-12 Thus nursing education must begin to wonder: maybe it is not all academic. Nursing education must evaluate whether current admission standards, focused on quantitative numbers, discern the students most likely to succeed in nursing from the students most likely to perform well on tests. As a major component of program evaluation is tied to a graduate's ability to pass the National Council Licensure Examination for Registered Nurses (NCLEX) on the first attempt, US nursing programs are under enormous pressure to admit students capable of succeeding on test day. ${ }^{13}$ Knauss and Wilson ${ }^{12}$ point out that multiple nursing scholars believe that admission standards should select students most capable of passing NCLEX. One could argue however, that first time NCLEX success and becoming a nurse who embraces both the art and the science of patient care are not one in the same. Therefore, if admission standards, focused solely on quantitative numbers, are unable to reduce attrition do nursing schools need to change their focus. 


\section{Current research: non-academic variables}

Internationally, a small amount of research into the inclusion and evaluation of qualitative factors for admission into nursing school has been conducted. Factors evaluated for effectiveness included the use of admission essays, admission interviews, academic self-confidence, and personality indicators. ${ }^{14-18}$

Sadler $^{14}$ examined the probability that themes within an admission essay could identify students unlikely to succeed in nursing education. The single site study of 236 newly enrolled nursing students evaluated themes within the students admission essays and compared themes from the essays of completers to non-completers. Prior to admission, the essays had been scored by members of the admission committee and awarded a point value between $0-20$ based on essay: organization, focus, development of ideas, standard English usage, and congruency of the ideas with values, norms, and behaviors of the nursing profession. ${ }^{14}$ Each essay was scored by multiple committee members and the scores were averaged to give the student an overall essay score. While there was no difference in admission GPA for completers $v s$ non-completers, admission essay scores of completers were significantly higher than non-completers. ${ }^{14}$ Qualitative analysis revealed two main themes that differed between the groups. Completers often cited a personal experience with nursing as the reason they wanted to be a nurse. ${ }^{14}$ Noncompleters did not include a personal experience with nursing but instead referenced nursing as something to 'do', rather than to ' $b e$ '. ${ }^{14}$ Sadler ${ }^{14}$ concluded that there was evidence of identifiable differences in essays written by completers $v s$ non-completers.

Despite the promising results of Sadler's research, additional subsequent research into admission essays could not be found. However, the trends Sadler ${ }^{14}$ uncovered are supported by the research of Trice and Foster. ${ }^{15} \mathrm{~A}$ high attrition rate had developed within a nursing school and most students were citing values and beliefs inconsistent with the profession of nursing as a reason for leaving the program..$^{15}$ Trice and Foster felt students had an unrealistic view of the profession of nursing and found that students who chose to leave the program lacked a true desire to care for others and embrace the role of a nurse..$^{15}$ After the implementation of admission interviews, Trice and Foster ${ }^{15}$ saw a decrease in non-academic attrition. The interviews allowed faculty an opportunity to identify students who lacked a true heart for nursing, a problem consistently noted in the program before admission interviews began. ${ }^{15}$ Identifying students who lacked a true heart for nursing supports a theme uncovered by Sadler ${ }^{14}$ as students in the non-completer group wrote about caring, compassion, and helping others as something nurses do rather than a personal action. ${ }^{14}$

Research into the ability of an admission interview to reduce attrition is mixed. Ehrenfeld and Tabak ${ }^{16}$ and Trice and Foster ${ }^{15}$ both concluded that admission interviews decreased non-academic attrition. However, Timer and Clauson ${ }^{17}$ determined the opposite. All researchers noted the immense amount of time and resources needed to conduct interviews as a limitation of this particular admission criteria questioning whether a slight decrease in attrition was worth the resource allocation. ${ }^{15-17}$ While the interview process may not be an effective tool to significantly reduce attrition, studies exploring the admission interview process may have helped to uncover a missing link. Ehrenfeld and Tabak's ${ }^{16}$ longitudinal comparison of attrition rates for a nursing program during the transition from personal interviews, to group interviews, to no interview showed the lowest attrition rates when personal interviews took place. During the personal interviews, candidates were asked why they chose nursing. This question was not used in group interviews. ${ }^{16}$ While not a stated conclusion of Ehrenfeld and Tabak's ${ }^{16}$ research, the increase in attrition seen after the discontinuation of personal interviews may be related to the elimination of this screening question, which coincides with the research findings of Sadler $^{14}$ and Trice and Foster. ${ }^{15}$

An underlying theme of research related to admission essays and admission interviews was the ability of each to evaluate students with comparable academic performance and identify which student most embraced the art of nursing. Additional research into personality indicators, self-confidence and self-efficacy support this perspective. Nursing schools should be admitting students who can both thrive academically and embrace nursing as an art. In 2008, McLaughlin, Moutray, and Muldoon examined the role of personality and academic self-confidence in nursing school success using Eysenck's personality types. Incoming students completed questionaries' to test their occupational self-efficacy and personality. Results of completers and non-completers were compared. Students whose personality highly favored psychoticism, as defined by Eysenck, were more likely to be non-completers. By definition, caring and empathy are not typically seen in people high in psychoticism. ${ }^{18}$ In addition, psychoticism is typically descriptive of impulsive and apathetic individuals who have less confidence in their academic abilities. ${ }^{18}$ These individuals are more likely to drop out in the face of adversity, something commonly reported by nursing students. Research by Seago et al. ${ }^{9}$ supports the notion that individuals with minimal academic self-confidence are less likely to be successful in nursing school. ${ }^{9}$ Seago et al. ${ }^{9}$ found that a student's self-confidence was an accurate predictor of graduation from nursing school when used in combination with academic admission criteria. ${ }^{9}$ Research results conclude that nonacademic factors, specifically an individual's ability to live compassion, display empathy, persevere through challenges, and be a nurse, are essential to nursing school success.

\section{Conclusions}

Although studies into qualitative admission criteria in nursing exist, current supporting evidence is lacking. However, the research demonstrates strength in the central underlying theme of its findings: students who enter nursing school prepared to meet its academic challenges while embodying nursing as an art are more likely to be successful. ${ }^{9,14-16,18}$ While the importance of academic preparedness for students entering nursing school cannot be discounted, the presence of high attrition despite quantitative admission standards cannot continue to be ignored. While the science of nursing and the complexity of healthcare require that nursing schools admit the brightest and best, nursing education must not forget that nurses must possess a special blend of scientific knowledge and critical thinking ability, while fostering a personal connection with patients. Since US nursing schools currently have an abundance of applicants, schools must adopt admission criteria that evaluates potential nurses as both a scientist and an artist. If nursing schools begin to admit students that embrace, embody, and live the art of nursing, attrition may decrease benefiting the profession of nursing and the patients' nurses serve.

\section{References}

1. Carper BA. Fundamental patterns of knowing in nursing. ANS Adv Nurs Sci 1978;1:13-23.

2. Zander PE. Ways of knowing in nursing: the historical evolution of a concept. J Theory Constr Test 2007;11:7-11.

3. National League for Nursing. Findings from the annual survey of schools of nursing 2011-2012. Executive Summary [Internet]; 2013. Available from: http://www.nln.org/docs/defaultsource/professional-development-programs/execsummary2012.pdf?sfvrsn $=4$

4. American Association of Colleges of Nursing. New AACN data show an enrollment surge in baccalaureate and graduate 
programs amid a call for more highly educated nurses. Press Release; 2012. Available from: http://www.aacn.nche.edu/ news/articles/2012/enrollment-data

5. National League for Nursing. Retention rates for RN programs 2006-2007. Oneyear retention status of full time nursing students and full time US undergraduates by program/institution type [slide]; 2011. Available from: http://www.nln.org/newsroom/nursing-education-statistics/retention-rates-in-rn-programs

6. Williams MG. Attrition and retention in the nursing major: Understanding persistence in beginning nursing students. Nurs Educ Perspect 2010;31:362-7.

7. Newton SE, Smith LH, Moore G. Baccalaureate nursing program admission policies: Promoting success or facilitating failure? J Nurs Educ 2007;46;439-44.

8. Potolsky A, Cohen J, Saylor C. Academic performance of nursing students: Do pre- requisite grades and tutoring make a difference? Nurs Educ Perspect 2003;24:24650.

9. Seago JA, Keane D, Chen E, et al. Predictors of students' success in community college nursing programs. J Nurs Educ 2012;51:489-95.

10. Shulruf B, Wang YG, Zh YJ, Baker H. Rethinking the admission criteria to nursing school. Nurs Educ Today 2011;31:72732 .

11. Wolkowitz AA, Kelley JA. Academic predictors of success in a nursing program. $\mathrm{J}$ Nurs Educ 2010;49:498-503.

12. Knauss PJ, Wilson, PP. Predicting early academic success: HESI admissions assessment exam. J Prof Nurs 2013;29:S28-31.

13. Accreditation Commission for Education in Nursing. Accreditation manual [Intranet]; 2013. Available from: https://www.ncsbn.org/SC2013.pdf
14. Sadler, J. Effectiveness of student admission essays in identifying attrition. Nurs Educ Today 2003;23:620-7.

15. Trice LB, Foster PH. Improving nursing school diversity through use of a group admission interview. AORN J 2008;87:52232.

16. Ehrenfeld M, Tabak N. Value of admission interviews in selecting of undersgraduate nursing students. J Nurs Manag 2000;8: 101-6.

17. Timer JE, Clauson MI. The use of selective admission tools to predict students' success in an advanced standing baccalaureate nursing program. Nurs Educ Today 2011;31:601-6.

18. McLaughlin K, Moutray M, Muldoon OT. The role of personality and self-efficacy in the selection and retention of successful nursing students: a longitudinal study. J Adv Nurs 2008;61:211-21. 